\title{
The Effects of Radical Nephrectomy and Nephron Sparing Surgery on Glomerular Filtration Rate for the Patients who Underwent Surgery for Localized Renal Mass
}

\section{Lokalize Renal Kitle Nedeniyle Cerrahi Uygulanan Hastalarda Radikal Nefrektomi ile Nefron Koruyucu Cerrahinin Glomerüler Filtrasyon Oranı Üzerine Etkileri}

\author{
Ahmet Güdeloğlư ${ }^{1}$, Bülent Akdoğan²,Haluk Özen ${ }^{2}$ \\ ${ }^{1}$ Memorial Ankara Hastanesi, Ankara, Türkiye \\ ${ }^{2}$ Hacettepe Üniversitesi Tıp Fakültesi, Üroloji Anabilim Dalı, Ankara, Türkiye
}

Dergiye Ulaşma Tarihi: 17.10.2016 Dergiye Kabul Tarihi: 23.10.2016 Doi: 10.5505/aot.2016.93063

\begin{abstract}
ÖZET
Amaç: Bu çalışmada, radikal nefrektomi (RN) ile nefron koruyucu cerrahinin (NKC) uzun dönem böbrek fonksiyonları üzerine etkisini ortaya koymak amaçlanmıştır.

Hastalar veYöntem: Hacettepe Üniversitesi Tıp Fakültesi Üroloji Anabilim Dalı’nda Ocak 1990 - Nisan 2011 tarihleri arasında renal kitle nedeniyle ameliyat edilen 1016 hastaya ait veriler, retrospektif olarak incelenmiştir. Tanı anında metastatik olduğu bilinen 78 olgu çalışma dışı tutulmuştur.

Bulgular: Çalışmaya alınan olguların 579'u (\%61,7) erkek ve 359'u (\%38,3) kadındır. 624 olguya RN, 314 olguya NKC yapılmıştır. Hastaların ortalama takip süresi RN yapılan grupta 46.7 ay iken, NKC uygulanan grupta 39.9 aydır. Ortalama radyolojik tümör boyutu sirasıyla $75 \pm 33,5 \mathrm{~mm}$ ve $37,8 \pm 26 \mathrm{~mm}$ 'dir $(\mathrm{p}<0.001)$. Ortalama ameliyat süresi RN ve NKC grupları için sırasıyla 137.6 ve 139.5 dakikadır. NKC uygulanan grupta ortalama sıcak iskemi süresi $18,9 \pm 6,8$ (3-36) dakikadır. Uzun dönem takip sonunda RN yapılan gruptaki kreatinin değerindeki ortalama $0,51 \mathrm{mg} / \mathrm{dl}$ artış, NKC uygulanan gruptaki $0,39 \mathrm{mg} / \mathrm{dl}$ artıştan anlamlı şekilde daha fazladır $(\mathrm{p}<0.001)$. Uzun dönem takipte preoperatif GFR' $1 \geq 60$ olan hastaların halen GFR değerinin $\geq 60$ olarak devam etme oranları, RN ve NKC yapılan gruplarda sırasıyla \%47.6 ve \%74.8 olarak tespit edilmiştir (p<0.001).

Sonuç: Çalışmamızda GFR'de azalma oranının uzun dönemde RN yapılan hastalarda NKC yapılanlara göre daha fazla olduğu bulunmuştur. T1 renal tümörü olan birçok olguda RN ile bütün böbreği çıarmak fazladan tedavidir. T1 renal tümörü olan hastalarda teknik olarak mümkün oldukça parsiyel nefrektomi tercih edilmelidir. Anahtar kelimeler: Renal Hücreli Karsinom, Radikal Nefrektomi, Nefron Koruyucu Cerrahi, Glomerüler Filtrasyon Oranı
\end{abstract}

ABSTRACT

Objectives: The goal of this study was to demonstrate the long-term effects of radical nephrectomy (RN) and nephron sparing surgery (NSS) on kidney functions.

Patients and Methods: The medical records of 1016 patients who underwent kidney surgery from January 1990 to April 2011 at Hacettepe University School of Medicine, Department of Urology were retrospectively collected and analyzed. Metastatic 78 patients at presentation were excluded.

Results: Radical nephrectomy and nephron sparing surgery was performed in 624 and 314 cases, respectively. Male to female ratio was 579/314. The mean follow up was 46.7 and 39.9 months for RN and NSS, respectively. The mean radiological tumor size was $75 \pm 33,5 \mathrm{~mm}$ for $\mathrm{RN}$ and $37,8 \pm 26 \mathrm{~mm}$ for NSS $(\mathrm{p}<0.001)$. The mean duration of surgery for RN and NSS was 137 and 139 minutes, respectively. The mean warm ischemia time for NSS was 18.9 minutes. Serum creatinin level was increased $0.51 \mathrm{mg} / \mathrm{dl}$ and $0.39 \mathrm{mg} / \mathrm{dl}$ for RN and NSS after long-term follow up, respectively $(\mathrm{p}<0.001)$. Glomerular filtration rate $(\mathrm{GFR})$ was $\geq 60 \mathrm{ml} / \mathrm{min} / \mathrm{m}^{2}$ in $47.6 \%$ and $74.8 \%$ of RN and NSS patients in long-term follow up, respectively $(\mathrm{p}<0.001)$.

Conclusion: Decrease in GFR was more prominent in RN compared to NSS patients in long term. Therefore, removing the whole kidney for especially T1 renal tumours is over treatment in most cases. Partial nephrectomy should be preferred for all T1 renal tumours whenever technically feasible. 
Key Words: Renal Cell Carcinoma, Radical Nephrectomy, Nephron Sparing Surgery, Glomerular Filtration Rate

\section{Giriș}

Konunun devamındaki paragraf ikinci sütuna geçtiğinde başlık ile aynı hizada olacak (diğer paragraf ile değil)Böbrekte yer işgal eden en yaygın solid lezyon renal hücreli karsinomdur (RHK) ve tüm böbrek tümörlerinin yaklaşık \%90'1nı oluşturur (1). Yetişkinlerdeki tüm kanserlerin yaklaşık \%3'ünü oluşturan RHK, ürogenital sistemin en agresif tümörlerindendir ve prostat ile mesane kanserinden sonra 3 . sıklıkta görülür (2). Amerika Birleşik Devletleri verilerine göre tahminen her 75 kişiden biri hayatı boyunca RHK geliştirecektir ve bununla birlikte RHK erkeklerde kanserden ölümde 7. sırada iken kadınlarda 8. sıradadır (3). Sonuçta RHK toplum sağlığını azımsanmayacak ölçüde tehdit eden önemli kanserlerden biridir.

Geçmişte RHK hastaları sıklıkla hastalığa ait "klasik triad" olarak bilinen; hematüri, yan ağrısı ve ele gelen kitle gibi belirti ve bulgularla doktora başvururlardı ve bu hastalara uygulanan tek küratif tedavi radikal nefrektomiydi (4). Günümüzde olguların \%70'den fazlasını nonspesifik abdominal şikâyetlere sahip hastalara rutin olarak uygulanan görüntüleme tetkikleri sonucu tesadüfen saptanan olgular oluşturmaktadır. Özellikle son 20 yılda gelişen bu değişiklik, hastalığın evresinde ileri evreden erken evreye kaymaya sebep olmuştur.

Eskiden semptomatik RHK hastaları sıklıkla metastatik evrede yakalanırken ve kür olma şansını yitirirken günümüzde olguların çoğu hastalık henüz böbreğe lokalize halde iken tanı almakta ve uygulanan çeşitli nefron koruyucu cerrahi (NKC) yöntemlerle yüz güldürücü sonuçlar elde edilebilmektedir (5). Görüntüleme tekniklerindeki gelişme sadece tesadüfen saptanan renal kitle insidansinı artırmakla kalmamıș, aynı zamanda renal kitleler daha küçük boyutta yakalandıkları için, geçmiş dönemlere nazaran daha sik nefron koruyucu cerrahi yapılır hale gelmiştir.

Kronik böbrek hastalığ 1 (KBH) glomerüler filtrasyon oranının (GFR) $<60 \mathrm{ml} / \mathrm{dk} / 1,73 \mathrm{~m}^{2}$ olması şeklinde tanımlanır. Renal kortikal tümörlü hastalarda RN, KBH gelişimi için önemli bir risk faktörüdür (ㅁ). KBH'nın kardiyovasküler hastalık için bağımsız bir risk faktörü olduğu ortaya konulmuştur (7). Bununla birlikte KBH olan hastalarda kardiyovasküler mortalite, $\mathrm{KBH}$ olmayanlara göre daha fazladır (32/1.000'e karş1 16/1.000)(ㅇ). Genç (<65 yaş) ve küçük renal kitleli $(<4 \quad \mathrm{~cm})$ hastalarda RN ile NKC karşılaştırıldığında, RN'nin daha kısa genel sağkalım ile ilişkili olduğu gösterilmiştir (9). Görüntüleme ve ameliyat tekniklerindeki bu gelişmeler sonucunda günümüzde RHK hastalarında onkolojik başarı artık tek başına başarı olarak kabul edilemez. Asıl başarı kansere özgü sağkalım yanında; ameliyattan sonra korunan iyi bir renal rezerv ile genel sağkalımın da kanser dışı sebeplerle olumsuz etkilenmesini engellemektir.

$\mathrm{Bu}$ çalışmada, Hacettepe Üniversitesi Tıp Fakültesi Üroloji Anabilim Dalı'nda, 1990 y1lından 2011 y1lına kadar lokalize renal kitle nedeniyle cerrahi girișim yapılmış olan hastaların tüm verileri retrospektif olarak incelenerek, radikal nefrektominin ve NKC'nin böbrek fonksiyonunun en önemli göstergesi olan GFR üzerine etkilerini ortaya koymak hedeflenmiștir.

\section{Hastalar ve Yöntem}

Ocak 1990 ile Nisan 2011 tarihleri arasinda böbrekte yer işgal eden lezyon nedeniyle laparoskopik veya açık yöntemle $\mathrm{RN}$ veya NKC yapılan 1016 hastanın klinik ve demografik verileri retrospektif olarak incelenmiştir. Hastaların ameliyat öncesi, ameliyat sonrası erken dönem ve uzun dönem sonundaki GFR değerleri hesaplanarak, RN ve NKC'nin GFR değerleri üzerine olan etkileri ve bu cerrahilerden sonra kalan renal rezerv ile sağkalım ilişkisi ortaya konulmaya çalışılmış̦tır.

Tanı anındaki ve son kontrole geldikleri tarihteki üre, kreatinin değerleriyle Modification of Diet in Renal Disease (MDRD) çalışması formülüne göre hesaplanmış GFR değerleri incelenmiştir (10). MDRD çalışmasına göre GFR "GFR $=175 \mathrm{x}$ 
(serum kreatinin) $)^{-1.154} \times(\text { yaş) })^{-0.203} \times 0.742$ (eğer birey kadınsa)" formülü ile hesaplanmıştır.

Temel istatistiksel kavramlar ile hastaların özellikleri özetlenmiştir. Sayısal parametrelerin özetlenmesinde ortalama, standart sapma, ortanca, minimum ve maksimum değerleri gerekli durumlarda $\% 95$ güven aralıkları; kategorik değişkenler ise sayı ve yüzde değerleri kullanılmıştır. İstatistik anlamlılık sınırı (p) 0.05 olarak belirlenmiştir. İstatistiksel analizler SPSS ver 16.0 programı ile yapılmıştır.

\section{Bulgular}

Hacettepe Üniversitesi Tıp Fakültesi Üroloji Anabilim Dalı'nda Ocak 1990 - Nisan 2011 tarihleri arasinda renal kitle nedeniyle ameliyat edilen 1016 hastaya ait veriler retrospektif olarak toplanmıştır. Tanı anında metastatik olduğu bilinen 78 olgu çalışma dışı tutulup, 938 hastanın verileri incelenmiştir.

Çalışmaya alınan olguların 579 $(\% 61,7)$ 'u erkek ve $359(\% 38,3)$ 'u kadındır. 624 olguya $(\% 66,5) \mathrm{RN}, 314$ olguya $(\% 33,5)$ NKC yapılmıştır. Hastaların ortalama takip süresi $44.3 \pm 50.5$ aydır. $R N$ veya $\mathrm{NKC}$ yapılan hastaların yaş ortalaması sırasıyla $56,07 \pm 12,21$ y1l ve $51,87 \pm 12,25$ y1l olarak bulunmuştur $(p<0,001)$. Cerrahi uygulanan renal kitlelerin ortalama radyolojik boyutu RN yapilan grupta $75 \pm 33,5 \mathrm{~mm}$ (4-250) iken, NKC yapılan grupta $37,8 \pm 26 \mathrm{~mm}$ (10-240) olarak hesaplanmıştır $(\mathrm{p}<0.001)$. Ortalama ameliyat süresi $\mathrm{RN}$ için 137,6 $\pm 59,3$ (45-500) dakika iken NKC için $139,5 \pm 51,6 \quad(45-360)$ dakikadır. NKC uygulanan grupta ortalama sicak iskemi süresi $18,9 \pm 6,8 \quad$ (3-36) dakikadır. Patolojik incelemede RN yapilan grubun \%10,2'si benign iken NKC uygulanan grubun \%29'u benigndir $(p<0.001)$. Hastaların uzun dönem takiplerinde hastalıksız sağkalım RN yapılan grupta \%83,66 iken NKC uygulanan grupta $\% 97,23$ 'tür $(\mathrm{p}<0.001)$.

Preoperatif kreatinin ortalamas1 RN ve NKC uygulanan grupta sirasiyla $0,98 \pm 0,74 \mathrm{mg} / \mathrm{dl}$ $(0,2-11,85)$ ve $0,89 \pm 0,28 \mathrm{mg} / \mathrm{dl}(0,39-2,41)$ 'dir $(\mathrm{p}=0,135)$. Hastaların uzun dönem takip sonunda RN'de ve NKC'de kreatinin ortalamaları sirasiyla; $1,49 \pm 1,54 \mathrm{mg} / \mathrm{dl}$ ve $1,28 \pm 1,61 \mathrm{mg} / \mathrm{dl}$ 'dir $(\mathrm{p}<0.001)$. RN yapilan gruptaki ortalama $0,51 \mathrm{mg} / \mathrm{dl}$ artış, NKC uygulanan gruptaki $0,39 \mathrm{mg} / \mathrm{dl}$ artıştan anlamlı şekilde daha fazladır $(\mathrm{p}<0.001)$.

Hastaların preoperatif GFR değerlerine bakılmaksızın uzun dönem takip sonunda GFR değerleri incelendiğinde; $\mathrm{RN}$ yapılan hastalardan son kontrol bilgilerine ulaşabildiğimiz toplam 351 hastanın 145 (\%41.3)'inin GFR değeri $\geq 60$ iken, NKC uygulanan grupta ise 178 hastanı 124 (\%69.7)'ünün GFR değeri $\geq 60$ 'dır $(p<0.001)$ (Tablo 1).

Tablo 1. Ameliyat öncesi ve uzun dönem kontrolde GFR değerleri dağılımı

\begin{tabular}{|l|l|l|}
\hline Preop GFR & \multicolumn{2}{|c|}{ Uzun Dönem Kontrol GFR } \\
\hline & \multicolumn{1}{|c|}{$<\mathbf{6 0}$} & \multicolumn{1}{|c|}{$\geq \mathbf{6 0}$} \\
\hline $\begin{array}{r}\mathbf{R N} \\
<\mathbf{6 0} \mathbf{n}=\mathbf{5 5}\end{array}$ & $51(92,7)$ & $4(7,3)$ \\
$\mathbf{6 6 0} \mathbf{n = 2 9 6}$ & $155(52,4)$ & $141(47,6)$ \\
\hline $\begin{array}{r}\mathbf{N K C} \\
<\mathbf{6 0} \mathbf{n = 1 9}\end{array}$ & $14(73,7)$ & $5(26,3)$ \\
$\mathbf{2 6 0} \mathbf{n = 1 5 9}$ & $40(25,2)$ & $119(74,8)$ \\
\hline $\mathbf{p}$ & $<0,001$ & $<0,001$ \\
\hline
\end{tabular}

Ameliyat öncesi GFR değeri $\geq 60$ olan hastaların ameliyat sonrası da $\geq 60$ kalma oranlar1 RN (n:296) ve NKC (n:159) hastalarında sirasiyla \%47.6 ve \%74.8 olarak bulunmuştur $(p<0.001)$,(Şekil 1). Ameliyat öncesi GFR değeri $<60$ olan hastaların ameliyat sonras $1 \mathrm{da}<60$ kalma oranları $\mathrm{RN}$ ve NKC için sırasıyla \%92.7 ve \%73.7'dir. Uzun dönemde RN yapılan hastalar NKC uygulanan hastalara göre daha fazla oranda GFR $<60$ olma durumunu sürdürmektedir $(\mathrm{p}<0.001)$. 


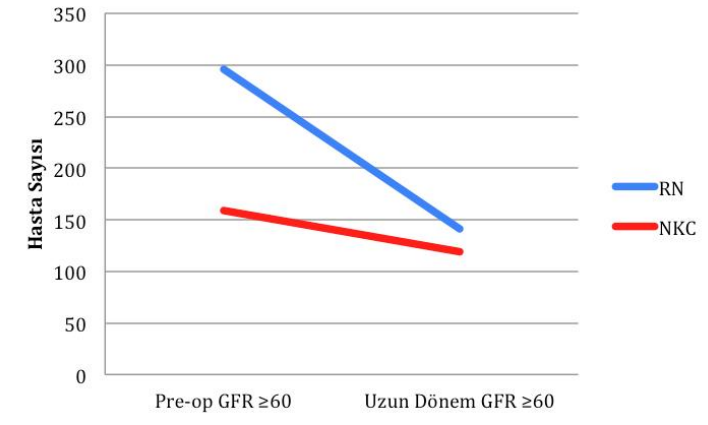

Şekil 1. Ameliyat öncesi GFR Değeri $\geq 60$ $\mathrm{mg} / \mathrm{dk} / \mathrm{m}^{2}$ olan hastaların uzun dönem GFR değerlerinin 60'ın üstünde kalma oranları

\section{Tartışma}

Renal hücreli karsinom insidansının artmasına, insidental erken tanı ile lokalize evreye doğru evre kaymasina, ameliyat tekniklerindeki gelişmelere ve daha fazla $\mathrm{RN}$ ve NKC uygulanmasına rağmen, RHK mortalitesi halen artmaktadır. Yaklaşık 34.500 hastanın incelendiği bir kohort çalışmasında yaşa uyarlanmış insidans 1983 'den 2002 yılına kadar 100.000'de 7,1'den 10,8'e yükselmiştir. $\mathrm{Bu}$ artışın da büyük bir kısmından $\leq 4 \mathrm{~cm}$ tümörler sorumludur. Boyutu $<2 \mathrm{~cm}$ ve $2-4 \mathrm{~cm}$ tümörlerin insidansı sirasiyla 100.000 'de 2'den 3 'e ve 1 'den 3.3 'e yükselmiştir. Bununla birlikte her tümör boyutuna ait kategoride böbrek cerrahisi, insidanstaki artışa paralel olarak artmıştır. Aynı çalışmada böbrek kanserine özgü ve genel mortalite oranları sirasiyla 100.000 'de 1,2 'den 3,2'ye ve 1,5 'den 6,5 'e yükselmiştir. Özellikle küçük tümörlerde daha fazla olmakla birlikte böbrek kanseri insidans1 artmasina ve buna paralel olarak böbrek kanseri cerrahisi daha sik yapılmasına rağmen, en azından küçük tümörlerde bile mortalite oranları artmaya devam etmiştir (11). Böbrek kanseri tedavisindeki bu güncel paradoks tüm küçük renal kitleli hastalara uygulanan cerrahi girişimlerin uygunluğunu sorgulatmaktadır.

Geçmişten beri süregelen yanlış düşüncelerden birisi de normal kontralateral böbreği olan hastalarda tümör tarafindan tutulmamış normal renal parankimin, $\mathrm{RN}$ ile feda edilmesine bağlı serum kreatinindeki kalıcı yüksekliğin, uzun dönemde ciddi yan etkiye neden olmayacağıdır. Bu düşüncenin oluşmasındaki en önemli sebep 20 yıldan fazla takip edilen donör nefrektomi yapilan hastalarda normal popülasyona kıyasla daha fazla oranda herhangi bir ciddi hastalık, diyaliz ihtiyac1 gerektirecek böbrek yetmezliği ve ölüm görülmediğinin bildirilmiş olması gerçeğidir (12). Böbrek donörleri ile böbrek tümörlü hastalar arasında dikkat edilmesi gereken önemli bir nüans, donörler pek çok komorbidite açısından taranmış, dikkatle seçilmiş sağlıklı ve sıklıkla genç ( $<40$ yaş) insanlar iken, böbrek tümörlü hastalar bu durumun tam tersi olarak, genellikle daha yaşl1 ve siklikla metabolik sendrom, hipertansiyon, koroner arter hastalığı, obezite ve diyabet gibi böbrek fonksiyonunu da etkileyebilecek çok çeşitli komorbiditelerden bir veya birkaçına sahiptirler.

Kronik böbrek hastalığı (KBH) insidansı ve prevalansı gün geçtikçe artan büyük bir sağlık problemidir. GFR değerinin $<60 \mathrm{ml} / \mathrm{dk} / 1,73 \mathrm{~m}^{2}$ olması şeklinde tanımlanan KBH'nin risk faktörleri; 60 yaşından büyük olma, hipertansiyon, diyabet, kardiyovasküler hastalık ve böbrek hastalığı aile öyküsüdür. Amerika'da günümüzde erken evre $\mathrm{KBH}$ 'ye sahip 19 milyon yetişkinin olduğu ve 2030 y1lında 2 milyonunun kronik diyalize veya renal transplantasyona gereksinim duyacağ 1 tahmin edilmektedir (15).

Toplum tabanlı büyük bir çalışmada tahmini GFR azaldıkça, ölüm, kardiyovasküler olay ve hastanede yatış riskinin arttığ gösterilmiştir (17). RN, KBY gelişimi için önemli bir risk faktörüdür. Küçük renalkortikal tümörlerin yaklaşı $1 \% 20$ 'sinin benign patolojiye sahip olduğu için, RN'nin artık altın standart yöntem olarak görülmemesi gerektiği kabul edilmiş bir gerçektir $(\underline{6}, \underline{18})$.

Mayo klinik ekibinin 2000 yılında tek taraflı RHK, diğer böbreği ve kreatinin değeri normal olan hastalarda RN ile NKC'yi karşılaştırdığ bir çalışmada kreatinin değerinin $>2 \mathrm{mg} / \mathrm{dl}$ olması ş̧eklinde tanımlandığı kronik renal yetmezlik, 10 y1ll1k takip sonunda RN grubunda \%22,4 iken NKC grubunda \%11,6 olarak bulunmuştur. Bununla birlikte RN grubunda daha fazla oranda protenüri olduğu da gösterilmiştir (\%55,2'ye karş1 \%34,5). RN'nin daha fazla kronik böbrek yetmezliği ve proteinüri riski taşıdığı ve NKC ile onkolojik sonuçlar açısından fark olmadığ 15 yıl önce Mayo klinikten bildirilmiştir. $\mathrm{Bu}$ nedenle 
normal kontralateral böbrekli ve tek taraflı RHK olan hastalarda NKC uygulanması gerekliliğini savunmuşlardır (21). Bundan 2 yıl sonra Memorial Sloan - Kettering Cancer Center'den bildirilen çalışmada, RN ve NKC yapılan hastaların ortanca 25 ay takip sonunda kreatinin değerinin $1,5 \mathrm{mg} / \mathrm{dl}$ ve $1,0 \mathrm{mg} / \mathrm{dl}$ olduğu bildirilmiştir $(\mathrm{p}<0.001)(\underline{22})$. Bizim verilerimizde de preoperatif kreatinin değerlerinde farklılık yok iken uzun dönem takipte kreatinin değeri ortalaması $\mathrm{RN}$ grubunda NKC grubundan daha fazladır.

Lokalize renal kitle nedeniyle 1995 ile 2005 y1lları arasında opere edilen 1.500 hastanın 10 yıldan fazla takip sonuçlarının incelendiği bir başka çalışmada ameliyat öncesi GFR, vücut kitle indeksi (VKI) ve komorbidite ile hastalıksız sağkalım arasında ilişki gösterilememiştir. Bununla birlikte hafif azalmış GFR $\left(45-60 \mathrm{ml} / \mathrm{dk} / 1,73 \mathrm{~m}^{2}\right)$ ve ciddi derecede azalmış GFR $\left(<45 \mathrm{ml} / \mathrm{dk} / 1,73 \mathrm{~m}^{2}\right)$ ile genel sağkalım arasında anlamlı ilişki gösterilmiştir (23). Küçük renal kitlelerde RN ile NKC'yi karşılaştıran bir başka çalışmada tüm yaş gruplarında genel sağkalımı benzer bulunmuş, hâlbuki 65 yaş altındaki 327 hastada NKC daha iyi sağkalıma sebep olmuştur ( $\mathrm{p}=0.002)$ (9). Yaklaşık $2550 \mathrm{RN}$ ve 550 NKC yapılan hastanın kardiyovasküler olay açısından karşılaştırıldığı bir çalışmada da RN yapilan grupta hem daha fazla oranda genel mortalite $(\% 32,1$ ' e karş1 $\% 19,8)$ hem de 1,4 kat artmış ilk kardiyovasküler olay riski olduğu gösterilmiştir (24).

Hacettepe verilerine göre ortalama kreatinin değerindeki artış uzun dönemde $\mathrm{RN}$ hastalarında NKC uygulananlardan daha fazladır ( $p<0.001)$. Preoperatif GFR'si $\geq 60$ olan hastalarda, bunun ameliyat sonras1 uzun dönemde 60'ın altına düşme oranı da $\mathrm{RN}$ yapılan grupta NKC uygulanan gruba göre daha fazladır $(p<0.001)$. GFR değerlerindeki bu anlamlı değişiklik bile yukarıdaki literatürde bahsedilen, $\mathrm{KBH}$, kardiyovasküler olay ve ölüm üçgeninde bizim elektif NKC yapma doğrultusunda duruşumuzu daha da sağlamlaştırmaktadır. İlerleyen yıllarda uzayan takip süreleri ile bu fark çok daha hissedilir düzeye ulaşacaktır. Onkolojik sonuçlardan ödün vermeden tedavi kararını belirlerken dikkat edilmesi gereken en önemli husus, böbrek fonksiyonlarının korunmasıdır. $\mathrm{Bu}$ bağlamda böbreğe lokalize RHK'nin güncel tedavisi; mükemmel sağkalım ve yüz güldürücü onkolojik sonucu nedeniyle

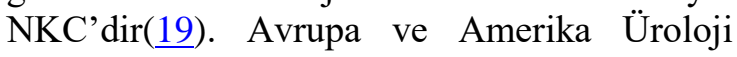
Dernekleri'nin kılavuzlarında T1 böbrek tümörü tedavisinde artık NKC altın standart yöntem olmuş ve komorbiditesi nedeniyle cerrahisi riskli olan hastalarda ablatif yöntemler ve izlem kendine yer bulmuştur (1) 20).

\section{Sonuç}

Tüm bu bilgiler 1şığında çalışma sonuçları özetlenecek olursa; günümüzde insidental olarak saptanan renal kitlelerin özellikle de lokalize olanların insidansı artmıştır. Buna paralel olarak NKC yapilma oranı da artmaktadır. Geçmişten beri süregelen $\mathrm{RN}$ deneyimi bize soliter böbrekte tümörü olan hastalarının daha fazla oranda $\mathrm{KBH}$ sürecine girdiğini göstermiştir. $\mathrm{KBH}$ sürecindeki hastalarda da daha fazla oranda kardiyovasküler olay ve buna bağl1 ölüm görüldügü literatür verileriyle ispatlanmış bir gerçektir. Lokalize böbrek tümörü nedeniyle $\mathrm{RN}$ ile NKC yapilan hastalar karşılaştırıldığında da kansere özgü sağkalımda fark yokken genel sağkalımın RN yapılan grupta daha düşük olmasının en rasyonel sebebinin bu hastalarda uzun dönem takipte gelişen $\mathrm{KBH}$ olması muhtemeldir.

Bizim verilerimize göre de $\mathrm{RN}$ yapılan hastalarda NKC uygulananlara göre GFR, uzun dönemde daha fazla oranda azalmaktadır. Bunun yanı sıra lokalize renal kitleler için NKC hala yeteri kadar siklikta yapılmamaktadır. Hastayı RN ile tümörden tamamıyla kurtardıkları için kendilerini kahraman olarak gören cerrahlar, uzun dönemde RN ameliyatının çok da masum bir işlem olmadığını hesaba katmalı ve teknik olarak çıkarılması mümkün olan her renal kitleye artık günümüzde lokalize böbrek tümörünün standart tedavisi haline gelmiş olan NKC işlemini uygulamalıdırlar.

\section{Çıkar Çatışması: Yok}




\section{Referanslar}

1. Ljungberg B, Cowan NC, Hanbury DC, Hora M, Kuczyk MA, Merseburger AS, et al. EAU guidelines on renal cell carcinoma: the 2010 update. European urology. 2010;58(3):398-406. Epub 2010/07/17.

2. Ferlay J, Shin HR, Bray F, Forman D, Mathers C, Parkin DM. Estimates of worldwide burden of cancer in 2008: GLOBOCAN 2008. International journal of cancer Journal international du cancer. 2010;127(12):2893-917. Epub 2011/02/26.

3. Jemal A, Siegel R, Ward E, Hao Y, Xu J, Thun MJ. Cancer statistics, 2009. CA Cancer J Clin. 2009;59(4):225-49.

4. Robson CJ, Churchill BM, Anderson W. The results of radical nephrectomy for renal cell carcinoma. The Journal of urology. 1969;101(3):297-301. Epub 1969/03/01.

5. Chen DY, Uzzo RG. Evaluation and management of the renal mass. Med Clin North Am. 2011;95(1):179-89. Epub 2010/11/26.

6. Huang WC, Levey AS, Serio AM, Snyder M, Vickers AJ, Raj GV, et al. Chronic kidney disease after nephrectomy in patients with renal cortical tumours: a retrospective cohort study. The lancet oncology. 2006;7(9):735-40. Epub 2006/09/02.

7. Sarnak MJ, Levey AS, Schoolwerth AC, Coresh J, Culleton B, Hamm LL, et al. Kidney disease as a risk factor for development of cardiovascular disease a statement from the American Heart Association Councils on kidney in cardiovascular disease, high blood pressure research, clinical cardiology, and epidemiology and prevention. Circulation. 2003;108(17):2154-69.

8. Shlipak MG, Fried LF, Cushman M, Manolio TA, Peterson D, Stehman-Breen C, et al. Cardiovascular mortality risk in chronic kidney disease: comparison of traditional and novel risk factors. JAMA. 2005;293(14):1737-45. Epub 2005/04/14.

9. Thompson RH, Boorjian SA, Lohse CM, Leibovich BC, Kwon ED, Cheville JC, et al. Radical nephrectomy for pT1a renal masses may be associated with decreased overall survival compared with partial nephrectomy. The Journal of urology. 2008;179(2):468-71; discussion 72-3. Epub 2007/12/14.

10. Tamura MK, Anand S, Li S, Chen S-C, WhaleyConnell AT, Stevens LA, et al. Comparison of CKD awareness in a screening population using the Modification of Diet in Renal Disease (MDRD) study and CKD Epidemiology Collaboration (CKDEPI) equations. Am J Kidney Dis. 2011;57(3):S17S23.

11. Hollingsworth JM, Miller DC, Daignault S, Hollenbeck BK. Rising incidence of small renal masses: a need to reassess treatment effect. J Natl Cancer Inst. 2006;98(18):1331-4. Epub 2006/09/21.

12. Najarian JS, Chavers BM, McHugh LE, Matas AJ. 20 years or more of follow-up of living kidney donors. Lancet. 1992;340(8823):807-10. Epub 1992/10/03.

13. Kaplan C, Pasternack B, Shah H, Gallo G. Agerelated incidence of sclerotic glomeruli in human kidneys. Am J Pathol. 1975;80(2):227-34. Epub 1975/08/01.

14. Bijol V, Mendez GP, Hurwitz S, Rennke HG, Nose V. Evaluation of the nonneoplastic pathology in tumor nephrectomy specimens: predicting the risk of progressive renal failure. Am J Surg Pathol. 2006;30(5):575-84. Epub 2006/05/16.

15. Coresh J, Selvin E, Stevens LA, Manzi J, Kusek JW, Eggers P, et al. Prevalence of chronic kidney disease in the United States. JAMA. 2007;298(17):2038-47. Epub 2007/11/08.

16. Suleymanlar G, Utas C, Arinsoy T, Ates K, Altun B, Altiparmak MR, et al. A population-based survey of Chronic REnal Disease In Turkey--the CREDIT study. Nephrol Dial Transplant. 2011;26(6):186271. Epub 2010/11/06.

17. Go AS, Chertow GM, Fan D, McCulloch CE, Hsu CY. Chronic kidney disease and the risks of death, cardiovascular events, and hospitalization. N Engl J Med. 2004;351(13):1296-305. Epub 2004/09/24.

18. Remzi M, Ozsoy M, Klingler HC, Susani M, Waldert M, Seitz C, et al. Are small renal tumors harmless? Analysis of histopathological features according to tumors $4 \mathrm{~cm}$ or less in diameter. The Journal of urology. 2006;176(3):896-9. Epub 2006/08/08.

19. Van Poppel H, Becker F, Cadeddu JA, Gill IS, Janetschek G, Jewett MA, et al. Treatment of localised renal cell carcinoma. European urology. 2011;60(4):662-72. Epub 2011/07/06.

20. Campbell SC, Novick AC, Belldegrun A, Blute ML, Chow GK, Derweesh IH, et al. Guideline for management of the clinical T1 renal mass. The Journal of urology. 2009;182(4):1271-9. Epub 2009/08/18

21. Leibovich BC, Blute M, Cheville JC, Lohse CM, Weaver AL, Zincke H. Nephron sparing surgery for appropriately selected renal cell carcinoma between 4 and $7 \mathrm{~cm}$ results in outcome similar to radical nephrectomy. The Journal of urology. 2004;171(3):1066-70. Epub 2004/02/10.

22. McKiernan J, Simmons R, Katz J, Russo P. Natural history of chronic renal insufficiency after partial and radical nephrectomy. Urology. 2002;59(6):81620. Epub 2002/05/29.

23. Pettus JA, Jang TL, Thompson RH, Yossepowitch O, Kagiwada M, Russo P. Effect of baseline glomerular filtration rate on survival in patients undergoing partial or radical nephrectomy for renal cortical tumors. Mayo Clin Proc. 2008;83(10):11016. Epub 2008/10/03.

24. Huang WC, Elkin EB, Levey AS, Jang TL, Russo P. Partial nephrectomy versus radical nephrectomy in patients with small renal tumors--is there a difference in mortality and cardiovascular outcomes? The Journal of urology. 2009;181(1):5561; discussion -2. Epub 2008/11/18. 